\title{
Differentiating infantile tumors with diffusion imaging
}

\author{
Mark D. Krieger, MD \\ Division of Neurosurgery, Children's Hospital of Los Angeles, California
}

I $\mathrm{N}$ this issue of the Journal of Neurosurgery: Pediatrics, Bader and colleagues address radiographic features that distinguish glioblastoma multiforme (GBM) from desmoplastic infantile tumors (DITs) in infants. ${ }^{2}$ The authors review the case logs of a single pediatric center over 30 years and identify 70 tumors in children younger than 1 year of age. Of this group, and within the study's inclusion criteria, the authors describe 2 cases of GBM and 3 cases of DIT. Both cases of GBM had restricted diffusion in the solid portion of the tumor, whereas none of the cases of DIT had restricted diffusion.

The authors should be commended for making a valuable contribution to the literature. With this paper in mind, treating physicians should recognize that tumors with restricted diffusion are more likely to be hypercellular and thus malignant, invasive, and well vascularized. This is particularly important when planning surgery for infants, in whom a catastrophic outcome may result from relatively small amounts of intraoperative blood loss. As the authors point out, this information is also useful in discussion of prognosis and treatment options.

These findings are certainly not unexpected. It is well recognized that malignant tumors restrict diffusion. This has previously been shown in pediatric ${ }^{4,7}$ and adult GBM, diffuse intrinsic pontine gliomas, supratentorial and infratentorial primitive neuroectodermal tumors, $, 3,5$ and metastatic malignancies. ${ }^{1}$ It is also well recognized that less malignant tumors have variable diffusion restriction. ${ }^{1,6}$

The utility of this information has its limits. This study is based on 5 patients, and thus might not be generalizable. Moreover, these are rare tumors, and heterogeneity would be expected, making universal findings unlikely. Radio- graphic findings might help favor a diagnosis, but in these cases they are not sufficiently substantiated to be the sole basis for diagnosis.

The explosion of available information from advanced imaging techniques is truly wonderful. In addition to diffusion mapping, we can use MR spectroscopy to detail the metabolic makeup of tumors and even to differentiate regions within a tumor; we can use perfusion imaging to detail tumor vascular patterns; and we can use nuclear scans to differentiate metabolic activity within the tumor. The goal and hope is that noninvasive imaging will eventually give us the full molecular profile of the tumor and allow us to target therapies without having to perform surgery. We are getting closer to this point, but we are not there yet.

This paper reminds us of the utility and limitations of advanced imaging techniques. It also demonstrates that the oldest diagnostic tests are still the most valuable: the history and physical examination. In this series, the infants with malignant tumors presented with fulminant signs and symptoms, whereas those with the benign lesions presented with asymptomatic macrocephaly.

http://thejns.org/doi/abs/10.3171/2014.11.PEDS14537

\section{References}

1. Al-Okaili RN, Krejza J, Wang S, Woo JH, Melhem ER: Advanced MR imaging techniques in the diagnosis of intraaxial brain tumors in adults. Radiographics 26 Suppl 1:S173-189, 2006

2. Bader A, Heran M, Dunham C, Steinbok P: Radiological features of infantile glioblastoma and desmoplastic infantile tumors: British Columbia's Children's Hospital experience. J Neurosurg Pediatr [epub ahead of print May 8, 2015. DOI: 10.3171/2014.10.PEDS13634] 
3. Chawla A, Emmanuel JV, Seow WT, Lou J, Teo HE, Lim CC: Paediatric PNET: pre-surgical MRI features. Clin Radiol 62:43-52, 2007

4. Donmez FY, Aslan H, Coban G, Ozen O, Agildere M: Multimodal MR imaging findings of a congenital glioblastoma multiforme. Childs Nerv Syst 28:1831-1833, 2012

5. Eralil G, Jones TL, Howe FA, Barrick TR, MacKinnon AD: Supratentorial PNET in adults: MRI can help distinguish from glioblastoma - DWI is key. Neuro Oncol 16:vi2, 2014

6. Pavlisa G, Pavlisa P, Rados M: Diffusion differences between pilocytic astrocytomas and grade II ependymomas. Radiol Oncol 45:97-101, 2011

7. Severino M, Schwartz ES, Thurnher MM, Rydland J, Nikas I, Rossi A: Congenital tumors of the central nervous system. Neuroradiology 52:531-548, 2010

\section{Response}

Ahmad Bader, MD, and Paul Steinbok, MBBS, FRCSC

Division of Pediatric Neurosurgery, University of British Columbia; and British Columbia's Children's Hospital, Vancouver, British Columbia, Canada

We thank Dr. Krieger for his comments. We agree with him completely. The main goal of our report was to point out the utility of the diffusion scan on MRI, since this is not commented on in many reports on different types of brain tumors. We hope that this will alert readers to the value of reviewing the diffusion scans in evaluating brain tumors in children. 